\title{
Article
}

\section{Students' Studying and Approaches to Learning in Introductory Biology}

\section{Debra Tomanek $^{* \dagger}$ and Lisa Montplaisir ${ }^{\ddagger}$}

\author{
*Department of Molecular and Cellular Biology, University of Arizona, Tucson, AZ 85721; and "Department of \\ Biological Sciences, North Dakota State University, Fargo, ND 58105
}

Submitted June 14, 2004; Revised July 28, 2004; Accepted August 11, 2004

Monitoring Editor: Karen Kalumuck

\begin{abstract}
This exploratory study was conducted in an introductory biology course to determine 1) how students used the large lecture environment to create their own learning tasks during studying and 2) whether meaningful learning resulted from the students' efforts. Academic task research from the K-12 education literature and student approaches to learning research from the postsecondary education literature provided the theoretical framework for the mixed methods study. The subject topic was cell division. Findings showed that students 1) valued lectures to develop what they believed to be their own understanding of the topic; 2) deliberately created and engaged in learning tasks for themselves only in preparation for the unit exam; 3) used course resources, cognitive operations, and study strategies that were compatible with surface and strategic, rather than deep, approaches to learning; 4) successfully demonstrated competence in answering familiar test questions aligned with their surface and strategic approaches to studying and learning; and 5) demonstrated limited meaningful understanding of the significance of cell division processes. Implications for introductory biology education are discussed.
\end{abstract}

Keywords: learning, studying, college, introductory biology, performance assessment

\section{INTRODUCTION}

Large lectures are the learning environments for many university-level introductory science courses. Students in these courses are generally expected to take responsibility for their own learning and to engage, with little direction from their instructors, in the work necessary to learn the information covered in the course. The disappearance of instructor-created learning tasks (e.g., written activities, homework questions) is likely one of the more striking differences that biology students encounter in their transition from high school to university science courses. The large lecture learning environments are often characterized by such features as brisk coverage of vast amounts of information, classes that meet two or three times per wk, 200 to 300 students enrolled in the same class, few instances of formative assessment of student understanding, and the

\footnotetext{
DOI: $10.1187 /$ cbe.04-06-0041

†Corresponding author. E-mail address: dtomanek@u.arizona.
} edu. absence of graded homework. In short, these learning environments look and feel significantly different from the science classes that students experienced in secondary schools. Undergraduate science students regularly acquire knowledge in these lecture learning environments, but not necessarily meaningful understanding (Birk and Foster, 1993; McDermott and Shaffer, 1992; McDermott et al., 1994). However, because large lectures are the preferred instructional settings for university-level introductory biology courses, we wanted to learn more about whether and how these learning environments support, with little direction from instructors, students' efforts to learn. That is, how successfully are university students managing to create their own opportunities for learning?

The purpose of this exploratory study was to 1) describe whether and how biology students used a large, introductory-level lecture course to create their own learning tasks and 2) determine whether meaningful learning resulted from the students' efforts. The findings were not intended to be generalized to all students in all university biology learning environments. Rather, the findings represent approaches to 
studying and learning outcomes demonstrated by a small group of typical students (Erickson, 1996). The first section of this article describes the theoretical framework that guided our investigation of students' approaches to learning and creation of study tasks. This is followed by the questions that framed the analysis, the methods used for data collection and analysis, the findings, a discussion of the findings, and a final section on implications of the study for introductory biology education.

\section{THEORETICAL FRAMEWORK}

The study was developed with respect to research on what students do as they study and learn the material presented in their classes. The research in this area is described differently depending on whether it is conducted at the $\mathrm{K}-12$ or postsecondary level of education. In the $\mathrm{K}-12$ research literature, a theoretical framework commonly used to study this phenomenon is referred to as academic work or academic tasks. In the postsecondary literature, this framework is usually referred to as student approaches to learning (SAL). We drew from both of these theoretical frameworks, described below, to develop this study.

Doyle (1983) has characterized the nature of academic work in $\mathrm{K}-12$ classrooms in terms of academic tasks. The construct of academic task has been a useful framework for studying the relationship between classroom context (e.g., the learning environment), the curriculum (e.g., that which is to be learned), and students' opportunities for learning. Academic task research focuses our attention on work that students are expected to accomplish in lessons. Doyle (1986) describes the anatomy of academic tasks in the following way:

\begin{abstract}
A task consists of: (a) a product, such as words in blanks on a worksheet, answers to a set of test questions, or an original essay; (b) operations to produce the product, for example copying words off a list, remembering words from previous instructions, applying a rule to generate words, or making up "descriptive" or "creative" words; (c) resources, such as directions to use notes from a previous lesson, consult a textbook, not talk to other students, or not use examples given in class; and (d) the significance or "weight" of a task in the accountability system of a class (e.g., a grammar exercise might count as a daily grade, whereas an essay might count at $15 \%$ of the grade for a six-week term).
\end{abstract}

Collectively, the features of teacher-created academic tasks communicate important information to students that directs what they do with the content they are to learn. In other words, tasks provide essential context for student work in classrooms. Tasks cue students to what they should pay attention to, rehearse, or retrieve, in successfully creating academic products. An implicit assumption is that knowledge accrues as students engage in and complete academic tasks in the curriculum. The more novel the task, the greater the degree of transfer required by the student in successfully completing it and the more likely that new and meaningful student ideas will develop (Bennett and Desforges, 1988; Doyle, 1988; Doyle and Carter, 1984). This finding does not appear to be dependent on subject matter area because similar findings have been published in science education (Lee and Anderson, 1993; Sanford, 1987) and mathematics education (Henningson and Stein, 1997; Herbst, 2003). In particular, educational researchers are learning how difficult it is for K-12 teachers to manage the classroom environment "system" in ways that sustain and support novel academic tasks and subsequent meaningful learning (Doyle and Carter, 1984; Henningson and Stein, 1997; Herbst, 2003; Stein et al., 1996).

However, the use of academic tasks to frame the teachercreated work that students complete and ultimately learn from is absent in the research literature on postsecondary learning and teaching. This is not surprising because academic tasks in $\mathrm{K}-12$ classrooms focus on teacher-created tasks rarely found in university courses. Unlike $\mathrm{K}-12$, postsecondary learning environments generally are built on the assumption that students are responsible for creating their own opportunities for learning. Instructor-created academic tasks in lectures, when they exist at all, usually take the form of brief group work sessions to solve problems or to engage students in peer discussion exercises. These opportunities, often referred to as active learning strategies, are provided by instructors to engage more students in thinking about concepts during the lecture, provide practice at solving problems, or give students practice explaining key ideas to peers (Dufresne et al., 1996; NRC, 2000 12-13; Wenk et al., 1997). Although most of us would agree that active learning strategies comprise good instructional practice, the "stakes" for engaging in these activities are generally quite low for students. In most cases, few resources are required, operations needed to complete the task are straightforward, success in the task is of little value in the course grading system, and there is seldom a graded product at the end. In our own teaching of university-level biology courses, we find that good students tend to appreciate these in-class activities as opportunities to exercise their thinking. In other words, our good students take advantage of the academic work opportunities that we create. However, our less motivated students often choose not to participate at all.

Somewhat related to task research, the postsecondary literature has a growing body of research on SAL. The SAL research has produced findings about a variety of factors that influence studying and student learning. For example, students' varied approaches to learning are a function of the course context in which the studying occurs, the content and demands of the learning tasks, and the motivation of the student (Biggs, 1987; Dornye, 2000; Jacobs and Newstead, 2000). Findings from the SAL research have also shown that students vary in their approaches to learning, usually from subject to subject, and that the variety of approaches can generally be described taxonomically with classifications referred to as deep, surface, and strategic approaches to learning (Biggs, 1987; Tait et al., 1997). A deep approach to learning is characterized by students' desires to understand, learn with meaning, and recognize underlying principles and connections among related principles. A surface approach to learning often involves students' memorizing information and doing only what is necessary to succeed on an upcoming assessment. A strategic approach to learning is accompanied by students' close attention to details such as expected test format, the structure of the content as laid out in the text, and close adherence to an instructor's guidelines for studying. Table 1 summarizes the characteristics of these student approaches to learning. Other SAL researchers have identified how students' perceptions of their course learning 
Table 1. Learning approaches in the SAL framework (taken from Rowe, 2002)

SAL category

Deep approach

Surface approach

Strategic approach
General description of the approach

Goal to understand, enthusiastic interaction with content, relating new ideas to previous knowledge, relating evidence to conclusions, examining the logic of the argument

Goal to complete task requirements, treating task as an external burden, unreflectiveness about purposes or strategies, focus on discrete elements without integration, failure to distinguish principles from examples, memorizing information for assessments

Goal to obtain highest possible grades, target work to perceived preferences of teacher, awareness of marking schemes and criteria, systematic use of previous papers in revision, organizing time and effort to greatest effect, ensuring right conditions and materials for study

environments (e.g., large lecture, active learning strategies by the instructor) coupled with their approach to learning (e.g., surface approach) influences what students learn (Donald, 1997; Wilson and Lizzio, 1997). As might be expected, a deep approach to learning is valued more highly by instructors than either a surface or strategic approach (Ramsden, 1992). Finally, but importantly, deep approaches to learning have been shown to be important prerequisites for self-directed learning (Candy, 1991).

The two theoretical frameworks also differ in their typical methods of data collection and analysis. The $\mathrm{K}-12$ task framework nearly always involves qualitative methods, usually significant classroom observations and inspection of individual (e.g., interview) and group (e.g., observations and recordings of conversations) approaches to completion of the academic work assigned by a teacher. The SAL framework from the postsecondary literature often uses quantitative methods, usually data collected from student questionnaires and inventories used widely in the field as reliable and valid measures of students' perceptions of their learning environments and their own approaches to learning. The questionnaire data are generally statistically analyzed to identify factors that align with one of the three levels of the SAL taxonomy (Biggs, 1993; Richardson, 1990). For example, "effective use of evidence" is a factor regularly found in positive correlation with students who adopt deep approaches to learning. An "achievement orientation" is a factor often found in positive correlation with students who adopt strategic approaches to learning.

The two theoretical frameworks reviewed above are clearly based on different assumptions about K-12 and postsecondary learning environments as well as different research methodologies. For purposes of framing this study, we decided to first rely on the task framework from the K-12 literature to look for and then characterize the academic work that students engage in to study and learn. We made this decision because we believed that observing classes and then interviewing a sample of introductory biology students from a large lecture course could simultaneously allow us to determine their approaches to studying and learning and the level of meaningful learning that had resulted from their learning efforts. Furthermore, we believed that the task framework could work as an analytical tool in studying student learning, even though the tasks were created by the student, rather than instructor, in the university lecture course. However, the SAL framework was a useful lens for drawing conclusions about the quality of learning demonstrated by a sample of students in the course (e.g., surface vs. deep approaches to learning).
Motivated by previous work on academic tasks and influenced by SAL research findings, the following questions were developed to frame data analysis in our study.

- What is the academic work of students in a large, introductory-level biology lecture course? What is the nature of the tasks that students create for themselves (e.g., the product of the work, the operations and resources used to accomplish the work, the significance of the work in the course's reward system)?

- Do the student-created studying tasks result in deep approaches to learning and subsequent meaningful learning?

\section{METHODS}

\section{Background}

This study was conducted in one of three lecture sections of an introductory cell and molecular biology course with a large enrollment for majors at a large southwestern research university. The class met for two 75-min lectures each wk for the duration of a 15 -wk semester. Student enrollment in the section was about 240. The course was required for several majors in biological, agricultural, and health sciences. Topics covered in the course included cell chemistry, cell parts and their functions, cell energetics and metabolism, cell division, genetics, gene expression, development, the immune system, and viral diseases. The unit of focus in the study was titled "Cell Division and Mendelian Genetics." Cell cycle and cell division were chosen as the subject topics in the study because the topics made up almost half of the instructional time in the lecture unit and the topics are common to all introductory biology courses.

The instructor, highly regarded by many students and faculty members, was a virologist and a long-time faculty member with several years experience in teaching the course. Our impressions of the quality of instruction in the course were favorable, given our observations of the class and our informal discussions with the instructor about the course and his perspectives on teaching. From our perspective, the instructor cared about student learning, worked hard to present the content in interesting ways, encouraged student questioning, and capably used a variety of instructional technologies to enhance his lectures.

\section{Data Collection and Analysis}

Sources of data used in the study included 1) observation notes, recorded separately by the two authors, from four lectures in the unit; 2 ) transcripts of the four audio-taped lectures; 3 ) results of preunit test and postunit test items completed by students in the class; and 4) transcripts of preunit and postunit interviews with 13 volunteer students. In addition, all Microsoft PowerPoint notes and old exams available for student use were also available for our use in the study.

Both researchers recorded notes during their observations of the four lectures. These notes were collected largely to enable communication with the student interviewees about how they used the lectures to create their own studying tasks. The first author focused 
her observations on the students' varying attention to the instructor's comments. She tried to reasonably interpret what students might be attending to during the lectures given general levels of attentiveness, the nature of any questions raised by students, and occasional comments overhead by sitting among groups of students. Notes from the first author's observations, in particular, were intended to serve as prompts for discussion of critical points in the lectures later during the student interviews. Below is an excerpt from the first author's notes on the first day of the unit.

Dr. $\mathrm{H}$ is describing to us the "vocabulary" of chromosomes. He is drawing our attention to a diagram of chromosomes and nucleosomes. I like the metaphor he is using, the telephone cord coiling, to make his point about the supercoiling of the DNA molecule. It makes sense. Students are paying close attention to what he says. And when he writes words on the board most students also write the comments on their web notes. He is emphasizing the words chromatin and chromosome. The operational definitions that $\mathrm{Dr}$. $\mathrm{H}$ is providing seem clear. However, I wonder what he means when he just said that we will use the word "chromosome" in two different ways over the next few days. (Observer I's notes; excerpt from Day 1)

The second author focused her observations on the instructor's behaviors. She recorded the activities that the instructor used during the lectures and the approximate time at which they were implemented, recorded the questions posed by students and the instructor, and took note of the figures used by the instructor to illustrate explanations. These records, in particular, were intended to provide a history of lecture activities that could be discussed later in interviews between students and the second author. An example of some of the information summarized from her observation notes is presented in Table 2.

The eight preunit multiple choice test items were extracted from old exams provided by the instructor on the topics that would be covered in the unit. The preunit test was given to students during the last $15 \mathrm{~min}$ of class approximately $1 \mathrm{wk}$ before the unit began. One hundred seventy-nine of the approximately 240 students enrolled in the class voluntarily took the preunit test. The second author explained the study to the students and assured them that the pretest scores would not be counted in their course grades, but that she and the instructor would appreciate their best efforts in answering the questions. Students who were interested in being interviewed on two occasions in the study were asked to write their

Table 2. Topic coverage in the four-lecture unit on cell cycle, cell division, and introductory genetics

\begin{tabular}{|c|c|c|}
\hline Lecture & $\begin{array}{l}\text { Min (75 min } \\
\text { per lecture) }\end{array}$ & Topic \\
\hline
\end{tabular}

15

Class start-up (questions about last week's exam)

28 Chromosome structure and function

12 Cell cycle: timing and regulation

20 Cell division: mitosis

$2 \quad 65$

Cell division: mitosis and meiosis

10 Introduction to genetics: Mendel's work

34 Class start-up

11 Introduction to genetics: Mendel's work and genetics

$\begin{array}{ll}30 & \text { Terminology } \\ 22 & \text { Monohybrid problem }\end{array}$

$\begin{array}{cl}22 & \text { Monohybrid proble } \\ 8 & \text { Dihybrid problems }\end{array}$

$4 \quad 13 \quad$ Class start-up (details about upcoming exam)

15 Gene interactions

$47 \quad$ Gene linkage e-mail addresses on the backs of their preunit tests. The items used as a postunit test of student knowledge were chosen from the test that all students completed at the end of the unit. Six items were chosen representing ideas on cell cycle and cell division.

Eighty-six students indicated their interest in being interviewed for the study by providing their e-mail addresses. These students were contacted via e-mail by the second author about the times available for the first round of interviews that were to be conducted over the upcoming wk. Thirty-one students contacted the second author confirming that they would be available during the scheduled interview wks. However, individual scheduling difficulties reduced the number of volunteers to 14 . This number was further reduced to 13 in the final data set because one student who completed the first interview was unable to attend the second interview after the postunit test.

The second author conducted two complete interviews with each of 13 volunteer students. The first interviews lasted between 20 and $30 \mathrm{~min}$ and occurred during the wk prior to the beginning of the four-lecture unit. Interviewees were asked to think aloud about their reasons for the choices they had made on the eight preunit test questions about cell division and genetics. The second interview occurred in the wk after students had completed the unit exam on the material. Prior to the second interviews, the researchers reviewed their observation notes to assemble a list of discussion prompts, if necessary, about specific occurrences during the four lectures related to anything that the interviewee might bring up. To begin the second interview, students were asked about how they studied, the resources they used, and what they attended to during lectures. Then, as was the case with the first interviews, students were asked to explain their choices to six questions that they had answered on the end-of-unit exam. They were asked to think aloud as they described their reasoning for their choices. Then, the students were asked two more questions, developed earlier by the researchers, to probe the students' understanding of a cell division problem that had been used on the exam. The additional questions, described later in this paper, were designed to assess student understanding, as opposed to recall, of ideas associated with the topic.

Pre- and postunit student interview transcripts were coded for comments related to students' studying and efforts to learn, as well as for comments about the resources and operations used by students in the studying tasks that they created. Student responses to pre- and postunit test items were scored, and interviewed students' explanations of their reasoning for item choices were summarized and tallied. Interview transcripts were coded for comments relating to cell cycle and cell division problem reasoning in particular.

\section{FINDINGS}

\section{Students' Studying Tasks and Approaches to Learning}

The academic work in which students engaged was in preparation for the end-of-unit exam. All interviewed students in the study used the exam as the primary reason for deliberately organizing and systematically thinking about the content to be learned. The exams in the course were the major components of final grades for the course. However, all of the interviewed students expressed at least some interest in the content, especially in the ways in which it was presented during lectures. The instructor's lectures were perceived as interesting and informational by most of the students that were interviewed. Nearly all of the interviewed students said they tried to "understand," rather than take notes, as their professor explained ideas, especially when he used diagrams or other visual representations in his explanations. Because most of them had made paper copies of the PowerPoint slides prior to the lectures, these students felt they could listen more and write less than is the case in classes where notes are not provided ahead of time. Twelve of the 13 students stated that as they listened to their instructor's explanations, they were not thinking about the exam. 
Once in a while I think about the upcoming test as he is lecturing. But, only when we are close to the test day. Mostly I just try to concentrate on understanding what he is talking about. (Excerpt from interview with SI)

When I am sitting in class I am usually fascinated by what he is saying. He is easy to follow and I get excited when I can follow along with understanding. If he talks about something that I don't understand, I try to add it to the prepared notes so that I can ask questions or go back and look it up. (Excerpt from interview with JJ)

None of the interviewed students regularly created tasks for themselves either during lectures or on their own time that caused them to organize and then think more about the content to be learned. This deliberate activity occurred only in preparation for the exams, usually within $24 \mathrm{~h}$ just prior to exams. The one exception to the 24-h "rule" was a student who began studying about a wk before each exam in the course. His girlfriend was a biology major and he described how he would talk with her about his understandings of topics that he was studying. His girlfriend served a dual role of question-poser and reviser of his incomplete or incorrect ideas. An excerpt from the interview with this student is given below.

When I study for an exam I first read the book. I highlight in the book some of the major points he went over in class. It is a different way of thinking about what he talked about in class. Then I'll go through my notes and make flashcards of vocabulary words so I don't forget them. I guess I basically review my notes, do my flashcards, skim the book again. Also, my girlfriend is a biology major. So, I'll stop, when something is complicated like with mitosis and meiosis, and explain each step to her. She asks me questions and sometimes corrects me. It helps me to vocalize it, especially to someone who knows it. She is graduating soon and she knows this material. (Excerpt from interview with DT)

The task that this student created in preparation for the exam was more deliberate, involving more operations and

Table 3. Resources and operations used in studying for the exam (number of students given in parentheses)

Resources Used by Students in Studying for the Exam

Old exams available online (13/13)

PowerPoint lecture notes available online (12/13)

Additional handwritten notes added to the prepared

PowerPoint notes (11/13)

Textbook (8/13)

The discussion/review sessions during week prior to exam (1/13)

Operations Used by Student in Studying for the Exam

Answering questions on old exams (13/13)

Reading PowerPoint and additional lecture notes (12/13)

Reading textbook (8/13)

Highlighting with a marker what was perceived as important points in notes $(5 / 13)$

Explaining concepts to a peer $(1 / 13)$

Creating flash cards and verbally explaining the words to oneself $(1 / 13)$ resources than any of the other interviewees. Interestingly, this student was the only one of the 13 interviewed students to earn a perfect score on the end-of-unit exam.

In studying for the exam, students used a variety of resources and operations (see Table 3 ). With the exception of one, the students' use of resources and cognitive operations were compatible with surface or strategic approaches to learning.

All of the interviewed students relied heavily on the old exams as resources for studying tasks. For example, students valued the fact that the old tests alerted them to the type of questions that would be asked (e.g., multiple choice), the degree of difficulty that the questions would likely represent (e.g., remembering, applying an idea), and the content that was valued by the instructor through evidence of six of his prior exams (e.g., "I knew it would be heavy on genetics problems by looking at the old tests."). Students generally used the exams by answering the questions themselves and then going to the keys, also provided online, to check their answers. When their answers were incorrect, several of the students would return to their notes, and a few used their texts to review the sections in question. Almost all of the interviewed students also used the PowerPoint and additional handwritten lecture notes in studying, usually by simply reading them, but a few students highlighted with colored markers the points that they believed to be important given the emphases that the instructor had given the points during lectures. To a lesser extent, students read the textbook as they studied. Students claimed that the detail in the text was overwhelming and that it was generally easier to make sense of the text material after the instructor had explained the ideas in lectures. Several students also used the text to correct their answers to questions on the old tests that they had answered incorrectly. All of these strategies were compatible with surface or strategic approaches to learning.

Only one student demonstrated use of resources and some of the cognitive operations more compatible with a mixed surface/deep level approach to learning. For example, this student constructed flash cards to memorize what he perceived as significant terms from the unit. However, he also created opportunities to talk about his understanding with his more knowledgeable girlfriend, who would give him feedback. These think-aloud and talking-with-a-knowledgeable-other operations were unique in our study sample of students and represented strategies compatible with a deep approach to learning.

\section{The Learning Results}

Table 4 shows the three questions from the eight-question preunit test that asked students about concepts related to cell division. None of the preunit test questions related to cell cycle.

One hundred seventy-nine students in the class volunteered to take the eight-item multiple choice preunit test. These students generally performed poorly on these knowledge and comprehension level questions (Bloom et al., 1956), all of which represented concepts covered in high school general biology courses (see Table 5). The first author, in particular, has familiarity with high school biology curriculum through her several years of professional development work with teachers and her own 9 yr of high school biology teaching experience. 
Table 4. Preunit test questions about cell division (correct answers are in bold)

1. Why would you predict that half of the human babies born will be males and half will be females?

(a) Because of the segregation of the $X$ and $Y$ chromosomes during male meiosis.

(b) Because of the segregation of the $X$ chromosomes during female meiosis. (c) Because all eggs contain an $X$ chromosome.

(d) Because of the behavior of autosomes during meiosis. (e) Because all sperm contain a Y chromosome.

2. The molecules that make up a chromosome are:

(a) DNA and RNA. (b) DNA and proteins. (c) Proteins and lipids. (d) Nucleotides and nucleosides. (e) Proteins and phospholipids.

3. At the end of mitosis there will be ____ daughter cells, whereas at the end of meiosis there will be

(a) four, identical; two, nonidentical (b) two, identical; four, nonidentical (c) two, identical; two identical

(d) two, nonidentical; four, identical (e) four, identical; four, identical.

The 13 interviewed students were more successful than the larger population of students with the first and second questions, but less successful with the third question. The third question required understanding of a distinction that several of the interviewees claimed to be confused about: the difference between the cell division processes of meiosis and mitosis. Many of the interviewed students could not remember the difference between the cell division processes at the time of the preunit test. Only one student successfully reasoned the difference even though four of the 13 students chose the correct answer. An interview excerpt from a student who was confused and without an accurate explanation, but "guessed" correctly in the multiple choice question, is given below.

\begin{abstract}
In answering this question, you had to know the difference between mitosis and meiosis. Well, I remembered that during reproduction, cells are dividing. But, they divide in different ways. One way produces cells that are identical to the first cell. Another way produces different cells. I remembered that much. But, I don't know which is mitosis and which is meiosis. The number of resulting cells was also confusing. (Excerpt from interview with HF)
\end{abstract}

Table 6 shows six selected questions used as the study postunit test from the end-of-unit exam taken by all students in the class. These questions covered cell cycle and cell division. Questions 3-6 were asked in reference to the dividing cells diagram shown after Table 6 .

All students in the class $(n=240)$ took the end-of-unit exam. Students performed well on selected postunit test questions regarding the nuclear division processes of mitosis and meiosis: questions 2, 3, and 4 (see Table 7). These questions were similar to many questions that students had reviewed on the old tests. These were also concepts, especially questions 3 and 4, likely covered in high school biology. The particular questions represented familiar concepts asked in familiar forms.
Fewer students correctly answered questions 1, 5, and 6 . Questions 1 and 5 involved the recognition of stages in the cell cycle. The topic of cell cycle is covered less completely in high school biology than are the mechanisms of mitosis or meiosis. Therefore, students' prior knowledge about cell cycle might have been less well developed. However, this is difficult to state with confidence because no preunit test questions specifically asked about cell cycle, a deficiency in the study design that we later regretted. Also, similar questions probing students' understanding of what stages the diagrammed cells represented were not found in the Web notes, the lecture notes, or the old tests. These questions were unfamiliar. Therefore, students had not rehearsed the identification of cell cycle stages given diagrams of cells existing in different stages of the cycle. A majority of the students who answered question 5 incorrectly (both the class at large and the interviewed students) chose " $\mathrm{d}$ " as the answer, indicating that they interpreted all cells that were not in the process of nuclear division to be in the G1 stage of the cell cycle. Question 6 involved calculating the number of tetrads that would exist if a cell in the diagram were to undergo meiosis I. This type of question did not appear in the Web notes, the lecture notes, or the old tests. Additionally, it is difficult to state whether students had prior exposure in high school biology to thinking about meiotic cell division as a chromosome number reduction activity.

In addition, we asked the 13 interviewed students two additional unfamiliar questions about the dividing cells diagram that did not appear in the end-of-unit exam. The questions were added to further investigate whether students could apply their understanding of cell division to questions that they had not seen in class, on the Web notes, or on old exams:

1. Are these cells in mitosis, meiosis, or both? Explain.

2. Is it possible that any of these cells are gametes? Explain.

Five of the 13 students believed that the diagrammed cells demonstrated mitosis. Seven students said that it was not

Table 5. Student performance on preunit test items and their interview explanations

\begin{tabular}{|c|c|c|c|c|c|c|}
\hline & \multicolumn{3}{|c|}{ Preunit test questions about cell division } & \multicolumn{3}{|c|}{ Interview explanation of answers } \\
\hline & 1 & 2 & 3 & 1 & 2 & 3 \\
\hline No. of students in class who answered correctly (\%) & $52 / 179(.29)$ & $57 / 179(.32)$ & $65 / 179(.36)$ & NA & NA & NA \\
\hline No. of interviewed students who answered correctly (\%) & 6/13 (.46) & $7 / 13(.54)$ & $4 / 13(.31)$ & $1 / 13(.08)$ & 4/13 (.31) & $1 / 13(.08)$ \\
\hline
\end{tabular}


Table 6. Postunit test questions about cell cycle and cell division (from end-of-unit exam; correct answers are in bold)

1. Nuclear division occurs during:

(a) the G2 phase (b) mitosis or meiosis (c) the S phase (d) the G1 phase (e) the G0 phase.

2. The four haploid nuclei found at the end of meiosis differ from one another in their genotype. Some of this difference is the result of:

(a) cytokinesis (b) replication of DNA during the S phase (c) meiotic interphase (d) spindle formation

(e) random orientation of the tetrads during metaphase I of meiosis I.

3. How many of the cells in the figure are in metaphase?

(a) 0 (b) 2 (c) 3 (d) 5 (e) impossible to tell from these data.

4. How many of the cells in the figure are in anaphase?

(a) 0 (b) 2 (c) 3 (d) 5 (e) impossible to tell from these data.

5. How many of the cells in this figure are in G1?

(a) 5 (b) 10 (c) 12 (d) 21 (e) impossible to tell from these data.

6. If one of the cells diagrammed in this figure were to undergo meiosis, how many tetrads would be aligned at the metaphase plate during meiosis I?

(a) 2 (b) 3 (c) 4 (d) 6 (e) 8 .

The figure shown below represents a light microscopic view of a section of tissue containing cells that are actively progressing through the cell cycle. Using these data, answer questions 3-6.

possible to tell, and one student simply did not know. With the follow-up question about gametes, all of the students answered either "No" or that they could not tell. The explanations that the interviewed students gave to accompany their answers were generally framed in one of two ways (see Table 8). Some of the students used both the lack of tetrad formation and no evidence of four newly formed cells in the diagram to elaborate their answers. However, none of the interviewed students chose to include chromosome number reduction as a source of evidence in deciding whether meiosis or mitosis was occurring. One student was "bothered by the number of chromosomes" in elaborating her answer to the questions and changed her answer to the gamete question from "Yes" to "No" because of this puzzling situation. But, at no time during the interview did she state that she would expect to see some of the cells with only half

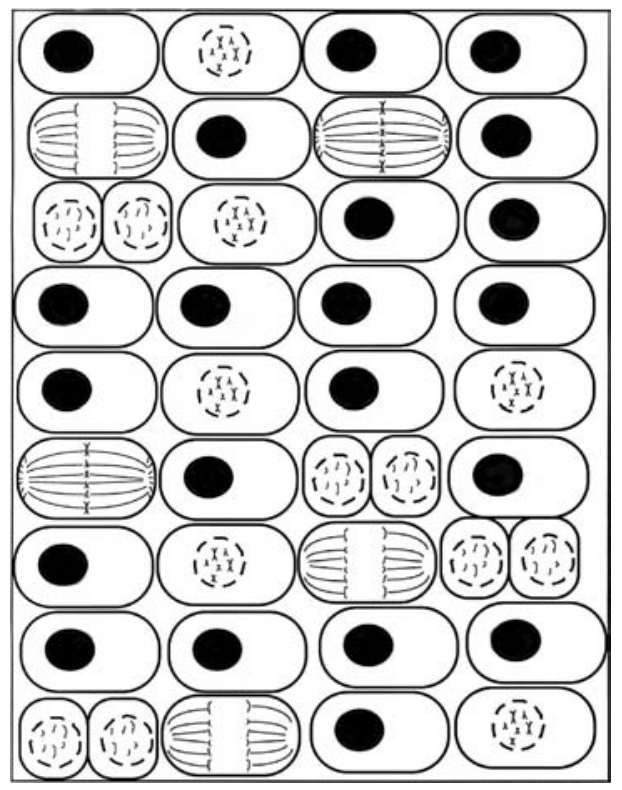

The Figure. of the number of chromosomes if indeed meiosis was demonstrated in the diagram. Rather, she simply recognized that "something about the number of chromosomes in all the cells" depicted in the diagram "bothered" her in thinking through her answer to the question.

Students' explanations of their answers to the two new questions about the diagram represented their attention to surface features of the cell division process rather than an understanding of what happens to sets of chromosomes during meiotic division. The reliance on surface features of the problem was also the case when students were asked in the postunit interview to describe the reasoning behind their answers to some of the genetics questions (not included in this particular article). The excerpts below are representative of the comments found in the data.

I think the cells are in mitosis because they [the chromosomes] are lining up single file at what appears to be metaphase. So, it is mitosis because in meiosis they line up in tetrads. And I don't see four new cells together, just two cells. (Excerpt from interview with BN)

You know, the cells in the diagram could be in mitosis or meiosis II. In meiosis II there is no tetrad formation. For example, in this cell [pointing to a cell in early prophase] you see the membrane breaking down at the start of prophase. This would be like prophase II. (Excerpt from interview with DT)

Without students' also acknowledging the important idea of chromosome number reduction in meiosis, it is difficult to claim that the students interviewed in this study understood meiosis in a meaningful way.

\section{DISCUSSION}

Students interviewed in this study claimed to use lectures to develop their understanding of cell cycle and cell division. Most of the interviewed students said that they focused on understanding their instructor's comments during lectures and did not necessarily align their listening with expectations about the upcoming exam. When the instructor gave cues about particular information for which they would be held accountable on the exam, the students did take note and wrote down the "cues." But the students that we interviewed 
Table 7. Student performance on postunit test items and interview explanations

Postunit test questions on cell cycle or cell division

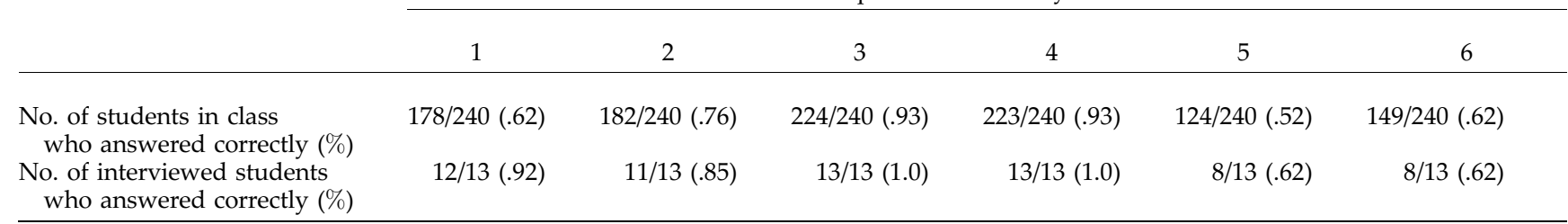

clearly believed that the lectures were opportunities to develop their own understanding. However, developing one's understanding by following an instructor's clear explanations during lectures is fundamentally different from developing understanding through self-explanation activities during studying (Chi et al., 1989).

It appears that the motivation for these good biology students to deliberately create study tasks outside of lecture time was the desire to succeed on the exam. The exam grades constituted a major portion of the course grade. Students' decisions about what and how to study were only slightly influenced, if at all, by the instructor's lectures. Rather, the students' decisions about what to use and how to study for the exam were tightly aligned with their expectations about the features of the upcoming exam, a behavior consistent with a strategic approach to learning. Given their experience with this instructor's first exam and their general trust that he would follow the same format and the same level of questioning, students engaged in study tasks that assured they could answer nearly any question given to them. Students did well with questions that resembled old exam questions and problems, but they did poorly with our new questions that were unfamiliar (i.e., not available in similar format in the old exams or other course resources), but not unrealistically difficult. The students performed poorly when asked to explain their reasoning for answers to our additional cell division questions during the postunit interview. This suggests that the students' studying successfully prepared them to excel only on questions that were familiar and expected.

Would students have engaged in deeper approaches to learning if they had not known what to expect, even if they still had the old exam and other course resources available to them? We suspect not. The university biology students in this study did not, for the most part, create tasks for themselves that resulted in the kind of understanding necessary to fully

Table 8. Student explanations of answers to the additional interview questions

No. answering

Tetrad formation (pairing of homologous chrom$8 / 13$ somes) in meiosis and not in mitosis.

Mitosis produces two cells and meiosis produces four cells.

Mitosis results in new cells with the same number of chromosomes whereas meiosis results in new cells with one-half the number of chromosomes. reason their answers to new and unfamiliar questions about cell division despite understanding was the goal of their engagement in lectures. Familiarity with what and how questions would be asked on the upcoming exam led to expectations that limited and contributed to the simplification of tasks that students created for themselves during their studying. We believe that this situation is similar to the difficulty that $\mathrm{K}-12$ teachers experience in creating and supporting tasks in their classrooms that result in meaningful learning among students (Doyle and Carter, 1984; Stein et al., 1996). The instructor in this course unknowingly reduced the cognitive demands of the student-created study tasks by assuring students that the upcoming exam was similar to what students had practiced with the resources (i.e., old exams and problems in the notes) available to them. However, the availability of old exams and expectations about a similar upcoming exam was not the only disincentive for adopting deep approaches to learning. The students were also unable to approach their learning in deep ways because they had little experience doing so. The interviewed students' comments about the resources and operations they used to study for exams suggests to us that they either did not 1) know how to study for meaningful learning or 2) feel that a new approach was necessary in order to be successful on the test.

\section{Implications for Introductory Biology Education}

Among undergraduates, particularly at the introductory course level, strategic and surface approaches to learning are common, whereas deep approaches to learning are uncommon. This common finding has resulted in recent calls by postsecondary education researchers for university faculty members to create learning environments that foster students' deep approaches to learning (Knight and Trowler, 2000; Kreber, 2003). Students, on their own volition, are unlikely to change the ways in which they approach their learning. The surface and strategic approaches to learning that the interviewed students used in this study worked well for them. They all earned good grades on their exams and only one of the 13 interviewed students engaged in any studying strategies that might be considered a strategy associated with a deep approach to learning. Why should they change how they study? If meaningful learning is to increase among students in large lecture biology courses, instructors must enable the change by taking the first step.

Students will not change their approaches to learning if 1) the studying strategies that they currently use provide the safest way to earn high grades on course assessments or 2) they do not know how to engage in deep approaches to learning. To change these situations, two instructional 
practices must change. First, instructors must increase the quality of their course assessments and the quantity and quality of their in-class activities. Second, and just as importantly, large lecture learning environments must provide students with opportunities to learn how to practice deep approaches to their own learning. This means that university instructors must be willing to accept the responsibility of teaching students more than biology. They must also accept the responsibility of teaching students how to learn in ways that will result in meaningful learning. We believe that this recommendation, more than any other in this paper, will be the idea that likely meets the greatest resistance among university biology instructors. After all, isn't it someone else's responsibility to teach students how to learn before they arrive at the university?

Several strategies can be employed to enable the ideas described above. First, instructors must create and consistently use graded assignments, quizzes, tests, or other assessments that demand a high level cognitive operations at an appropriate level for student learning in the course. The expectations for learning beyond remembering must be clear and understood by students. This should involve creating questions that require students to think about concepts in unfamiliar ways that have not been presented directly in lectures or other course resources. Second, regular and frequent in-class exercises in solving novel problems must be implemented in the lectures. The in-class exercises should carry some weight by being graded with substantive evaluative feedback. The academic task research has shown that without some "weight in the accountability system of a class" (Doyle, 1988), students are not likely to fully engage in the cognitive processes required to solve novel problems. Additionally, in-class time should be devoted to students' identifying, in public ways, what they had to know to solve the problem and how they went about solving it. This inclass activity models metacognitive strategies that have been associated with positive effects on students' meaningful learning (NRC, 2000 67-68).

The results of this exploratory study suggest to us that well-intentioned students in introductory biology believe that lectures allow them to develop their own understanding of topics in the course. However, the students' deliberate approaches to learning in preparation for exams (i.e., studying) are only minimally affected by lectures. Furthermore, the students' approaches to learning do not result in meaningful learning. Rather, motivation to succeed on graded, high-stakes assessments, such as exams, drives the ways in which students study and approach their learning outside of lectures. Unfortunately, students are not practicing deep approaches to learning. This results in rote knowledge, a less desirable learning outcome than deep understanding. We suggest that instructors in introductory biology lecture courses 1) teach students how to develop deep approaches to learning, and 2) implement assessment strategies that foster students' use of deep approaches to learning.

\section{REFERENCES}

Bennett, N., and Desforges, C. (1988). Matching classroom tasks to students' attainment. Elem. School J. 88(3), 221-234.

Biggs, J.B. (1987). Student Approaches to Learning and Studying. Hawthorne, Victoria: Australian Council for Educational Research.
Biggs, J.B. (1993). What do inventories of students' learning processes really measure? A theoretical review and clarification. Br. J. Educ. Psychol. 63, 3-19.

Birk, J.P., and Foster, J. (1993). The importance of lecture in general chemistry course performance. J. Chem. Educ. 70, 180-182.

Bloom, B.S., Englehart, M.B., Furst, E.J., Hill, W.H., and Krathwohl, D.R. (1956). Taxonomy of educational objectives: the classification of educational goals. In: Handbook I: Cognitive Domain. New York: Longmans Green.

Candy, P. (1991). Self-direction for lifelong learning. San Francisco: Jossey-Bass.

Chi, M.T.H., Bassok, M., Lewis, M.W., Reimann, P., and Glaser, R. (1989). Self-explanations: how students study and use examples in learning to solve problems. Cogn. Sci. 13, 145-182.

Donald, J.G. (1997). Improving the Environment for Learning. San Francisco: Jossey-Bass.

Dornye, Z. (2000). Motivation in action: towards a process-oriented conceptualization of student motivation. Br. J. Educ. Psychol. 79, 519-538.

Doyle, W. (1983). Academic work. Rev. Educ. Res. 53, 159-199.

Doyle, W. (1986). Content representation in teachers' definitions of academic work. J. Curric. Stud. 18(4), 365-379.

Doyle, W. (1988). Work in mathematics classess: the context of students' thinking during instruction. Educ. Psychol. 23, 167-180.

Doyle, W., and Carter, K. (1984). Academic tasks in classrooms. Curric. Inquir. 14(2), 129-149.

Dufresne, R.J., Gerace, W.J., Leonard, W.J., Mestre, J.P., and Wenk, L. (1996). Classtalk: a classroom communication system for active learning. J. Comput. Higher Educ. 7, 3-47.

Erickson, F.E. (1996). In: Handbook of Research on Teaching, 3rd, ed., ed. Merlin C. Wittrock. New York, NY: Macmillan.

Henningson, M., and Stein, M.K. (1997). Mathematical tasks and student cognition: classroom-based factors that support and inhibit high-level mathematical thinking and reasoning. J. Res. Math. Educ. 28(5), 524-549.

Herbst, P.G. (2003). Using novel tasks in teaching mathematics: three tensions affecting the work of the teacher. Am. Educ. Res. J 40(1), 197-238.

Jacobs, P.A., and Newstead, S. (2000). The nature and development of student motivation. Br. J. Educ. Psychol. 20, 243-254.

Knight, P.T., and Trowler, P.R. (2000). Department-level cultures and the improvement of learning and teaching. Stud. Higher Educ. 25, 69-83.

Kreber, C. (2003). The relationship between students' course perception and their approaches to studying in undergraduate science courses: a Canadian experience. Higher Educ. Res. Devel. 22(1), 57-75.

Lee, O., and Anderson, C.W. (1993). Task engagement and conceptual change in middle school science classrooms. Am. Educ. Res. J. 30(3), 585-610.

McDermott, L.C., and Shaffer, P. (1992). Research as a guide for curriculum development: an example from introductory electricity: part I: investigation of student understanding. Am. J. Phys. 60, 9941003.

McDermott, L.C. Shaffer, P., and Somers, M. (1994). Research as a guide for curriculum development: an illustration in the context of Atwood's machine. Am. J. Phys. 62, 46-55.

National Research Council. (2000). In: How People Learn: Brain, Mind, Experience, and School, ed. J.D. Bransford, A.L. Brown, and R.R. Cocking. Washington, DC: National Academy Press. 
Ramsden, P. (1992). Learning to Teach in Higher Education. London: Routledge.

Richardson, J.T.E. (1990). Reliability and replicability of the approaches to studying questionnaire. Stud. Higher Educ. 15, 155-168.

Rowe, J.W.K. (2002). First year engineering students' approaches to study. Int. J. Elec. Eng. Educ. 39(3), 201-209.

Sanford, J.P. (1987). Management of science classroom tasks and effects on students' learning opportunities. J. Res. Sci. Teach. 24(3), 249-265.

Stein, M.K., Grover, B.W., and Henningsen, M. (1996). Building student capacity for mathematical thinking and reasoning: an analysis of mathematical tasks used in reform classrooms. Am. Educ. Res. J. 33, 455-488.
Tait, H., Entwistle, N., and McCune, V. (1997). ASSIST: a reconceptualization of the approaches to studying inventory. In: Improving Student Learning: Improving Students as Learners, ed. C. Rust. Oxford: The Oxford Centre for Staff and Learning Development.

Wenk, L., Dufresne, R., Gerace, W., Leonard, W., and Mestre, J. (1997). Technology-assisted active learning in large lectures. In: Student-Active Science: Models of Innovation in College Science Teaching, ed. C. D'Avanzo and A. McNichols. Philadelphia: Saunders College Publishing, 431-452.

Wilson, K.L., and Lizzio, A. 1997. The development, validation, and application of the course experience questionnaire. Stud. Higher Educ. 22(1), 33-53. 